\title{
Reliability and Adequacy Assessment of a Transmission Network in the Eastern Croatia
}

\author{
Anto Topić, Srete Nikolovski, Emir Alibašić
}

\begin{abstract}
The paper analyzes network reliability and generator adequacy indicators using Monte Carlo simulation. The reliability indicators are analyzed for the eastern part of the Croatian transmission system and the influence of new combined cogeneration plants on the network reliability. All simulations were conducted with DIgSILENT PowerFactory software tool which uses two types of algorithms - state enumeration method and Monte Carlo simulation method. Firstly, two conditions of the transmission system were analyzed - the condition with the maximum and the condition with the minimum time varying load along with the comparison of the network reliability indicators. Then, new constructed combined-cogeneration plants connected at $\mathbf{4 0 0}$ $\mathrm{kV}$ busbars were compared to the combined-cogeneration plants of smaller size connected to the different point in the network at $110 \mathrm{kV}$ busbars. Results were compared and analyses show that the option with three CCGT is better than option of one huge CCGT plant placed in Ernestinovo or Slavonski Brod.
\end{abstract}

Index Terms-Monte Carlo Simulation; Reliability; Adequacy; Simulation; Transmission System; Cogeneration Gas Power Plants (CCGT).

\section{INTRODUCTION}

At the beginning of the electric power system reliability analysis, the methods of forming available source capacities, based on "Capacity outage tables" including the load duration curves, were used [1]. Their purpose was to analyze reliability indicators on hierarchical level 1 (HL I). The transmission network with power flows was included later on and it used Markov models of state space and analytical methods of defining the connection of network elements by the means of the minimal cut-set method and state enumeration methods [2]. The inclusion of power flows resulted in the real picture for the level of production with the transmission network on hierarchical level 2 (HL II). Finally, the distribution network and hierarchical level 3 (HL III) were included. Here, the systemic indicators for the whole network and the individual ones for customers and buses are defined [3]. This algorithm may be used as an additional criterion when choosing the best location to construct a new thermal power plant. Reliability indicators may have a significant influence even though they are not crucial. Some papers deal with the issue of reliability of some parts of a power system such as a power plant [4].

Monte Carlo simulation method calculates the reliability

Published on October 1, 2017

S. Nikolovski is with the J. J. Strossmayer University of Osijek, Faculty of Electrical Engineering, Computer Science and Information Technology (srete@etfos.hr).

A. Topić was with the J. J. Strossmayer University of Osijek, Faculty of Electrical Engineering, Computer Science and Information Technology (atopic@etfos.hr).

E. Alibašić is with the ZZO Tuzla Kanton, (emir.alibasic@gmail.com) indicators by simulating the real process and stochastic system behavior. The method treats a problem as a series of linked experiments. Both analytical-state enumeration method [5] and simulation methods have advantages and disadvantages. Generally, provided complex operating conditions have not been taken into consideration and/or the probability of component outages are very low (e.g. if a system is very reliable), hence analytical techniques are more efficient [6],[7]. However, if operating conditions are complex and/or the number of serious outages is high, it is better to use Monte Carlo simulation method. Monte Carlo simulation is the basic algorithm for many tools which analyze the transmission system reliability. Also, an additional technique can be used for the same purpose [8][10]. One of the known tools for this purpose is DIgSILENT PowerFactory which was used in this paper [11].

\section{AlGORITHM DESCRIPTION}

\section{Theoretical background}

The most important parameter in the assessment of reliability is the mathematical expectation of the stated reliability indicator [6], [7]. Therefore, the main features of Monte Carlo simulation method for the reliability assessment may be discussed from the point of view of expectation. If $Q$ is the unavailability function of the system and if $x_{i}$ is "zero - one" indicator of the variable, then

$$
\begin{array}{ll}
x_{i}=0 & \text { if the system is on } \\
x_{i}=1 & \text { if the system is off. }
\end{array}
$$

The assessment of unreliability or unavailability of the system is given by the equation

$$
\bar{Q}=\frac{1}{N} \sum_{i=1}^{n} x_{i}
$$

Where $N$ is the number of system conditions samples. Then, the real variance of the sample equals

$$
V(x)=\frac{1}{N-1} \sum_{i=1}^{N}\left(x_{i}-\bar{Q}\right)^{2}
$$

When the sample size is big enough, (3) may be approximated by the expression

$$
V(x)=\frac{1}{N} \sum_{i=1}^{N}\left(x_{i}-\bar{Q}\right)^{2}
$$

Since $x_{i}$ is "zero - one" variable, it follows that

$$
\sum_{i=1}^{N} x_{i}^{2}=\sum_{i=1}^{N} x_{i}
$$

If one inserts (2) and (5) into (4), one gets 


$$
\begin{gathered}
V(x)=\frac{1}{N} \sum_{i=1}^{N} x_{i}{ }^{2}-\frac{1}{N} \sum_{i=1}^{N} 2 x_{i} \bar{Q}+\frac{1}{N} \sum_{i=1}^{N} \bar{Q}^{2} \\
V(x)=\bar{Q}-2 \bar{Q}^{2}+\bar{Q}^{2} \\
V(x)=\bar{Q}-\bar{Q}^{2}
\end{gathered}
$$

It is important to notice that (2) provides only the assessment of system unreliability. The uncertainty of assessment may be measured by the variance of the expected assessment

$$
V(\bar{Q})=\frac{1}{N} V(x)=\frac{1}{N}\left(\bar{Q}-\bar{Q}^{2}\right)
$$

The level of accuracy of Monte Carlo simulation may be expressed as a coefficient of variation defined as

$$
a=\frac{\sqrt{V(\bar{Q})}}{\bar{Q}}
$$

Equation (7) may then be written as

$$
N=\frac{1-\bar{Q}}{a^{2} \bar{Q}}
$$

This equation indicates two important facts. For a certain desirable accuracy level $\alpha$, the necessary number of samples $N$ depends on the unreliability of the system but it is independent of the size of the system. Therefore, Monte Carlo method is appropriate for assessing the reliability of large systems. This is a significant advantage of the method in relation to analytic numerical techniques for the reliability assessment.

The unreliability (the probability of an outage) is in practical assessment of system reliability usually much smaller than 1 , so it follows that

$$
N \approx \frac{1}{a^{2} \bar{Q}}
$$

This means that the number of samples $N$ is approximately inversely proportional to the unavailability of the system. In other words, in case of a very high reliable system, a huge number of samples is necessary to satisfy the stated accuracy level.

\section{EFFICIENCY OF MONTE CARLO METHOD}

Various techniques of Monte Carlo method may be used to solve the same problem. This includes different methods of generating random numbers, different approaches to sampling and different techniques of variance decrease. Therefore, it is sometimes necessary to compare the efficiency of various Monte Carlo methods. If we consider two Monte Carlo simulations used for the assessment of the same system and the expected assessment of the reliability indicators, resulting from the implementation of these two methods, we will get indicators which are statistically the same. $t_{1}$ and $t_{2}$ represent the time of the calculation and $\sigma_{1}{ }^{2}$ and $\sigma_{2}{ }^{2}$ the variances of the reliability indicators for those two methods. If the ratio is

$$
\eta=\frac{t_{1} \sigma_{1}^{2}}{t_{2} \sigma_{2}^{2}}<1
$$

then the first method may be considered more efficient than the second. The efficiency of Monte Carlo method depends on the product of calculation time and assessment variance, meaning, it depends on the number of necessary samples.

When conducting the reliability assessment of power systems using Monte Carlo method, the calculation time and variance are directly connected to the chosen sampling technique and the needs of the system analysis to be done. Furthermore, we will discuss the sampling techniques, including the methods of generating random number (or random variable), techniques of variance decrease and various approaches to sampling. The purpose of this system analysis is to judge whether the condition of the system is good or bad.

\section{CONVERGENCE FEATURES OF MONTE CARLO METHOD}

\section{A. Convergence Accuracy}

Monte Carlo simulation creates an oscillating convergence process and we cannot be sure that a few samples will definitely mean fewer mistakes. Yet, it is correct that the connection of mistakes, i.e. the reliability range will decrease as the number of samples grows.

The variance of assessment expectation is given by (7). Standard deviation of the assessment is then

$$
\sigma=\sqrt{V(\bar{Q})}=\frac{\sqrt{V(x)}}{\sqrt{N}}
$$

This means that two measurements may be used to decrease the standard deviation in Monte Carlo simulation by increasing the number of samples and decreasing the variance of the sample. The technique of changing the variance may be used to improve the efficiency of Monte Carlo simulation. The variance may be decreased to zero, so it is always necessary to use a reasonable and big enough number of samples.

\section{B. Convergence Criterion}

The coefficient of variation shown in (8) is often used as a convergence criterion in Monte Carlo simulation. In the assessment of the power system reliability, different reliability indicators have different convergence speeds. It has been concluded that the coefficient of variation of the indicator EENS has the lowest convergence speed. This coefficient of variation should, therefore, be used as the convergence criterion in order to get reasonable accuracy when researching multiple indicators.

\section{ANALySIS OF THE TRANSMISSION NETWORK RELIABILITY}

This paper analyzes the transmission network reliability of the Croatian Transmission System Operator in the eastern part of Croatia [11]. The transmission network includes all 110, 220 and $400 \mathrm{kV}$ lines (overhead lines and cables). The transmission network is a part of the Croatian Power System which consists of substations, switchgears and aerial lines and cables. It is to be mentioned that only the eastern part of Power System, namely the transmission area Osijek, has a negative average rate of maximum load 
increase. In this paper, the transmission network (Fig. 1) of the transmission area Osijek which includes $400 \mathrm{kV}, 220$ $\mathrm{kV}, 110 \mathrm{kV}$ lines as well as all switchgears is to be analyzed [12]. From the perspective of a transmission network, switchgears are nodes with connected loads which also are to be shaped in this reliability analysis.

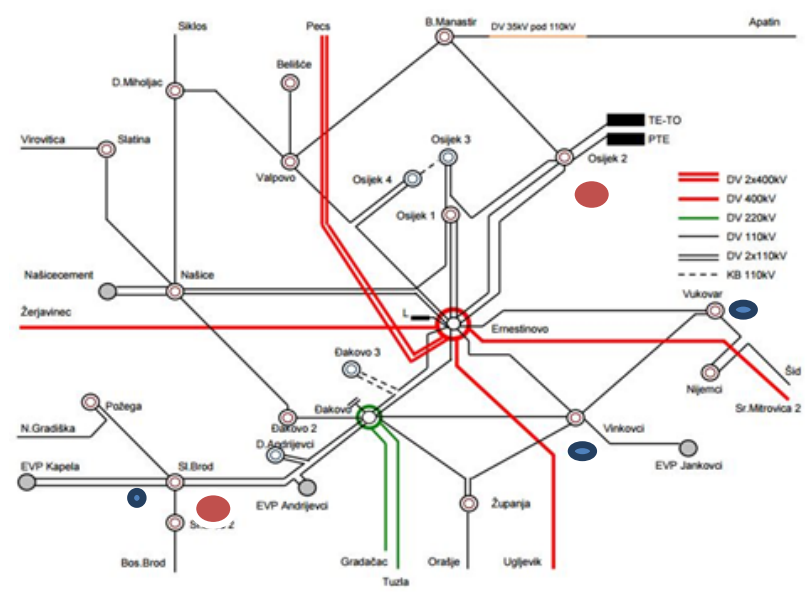

Fig. 1. Scheme of the analyzed transmission network

\section{RELIABILITY ANALYSIS FOR DIFFERENT LOADS}

This paper analyzes the change of the network reliability indicators upon the change of a network load and upon the connection of new power plants. The analysis was done by using DIgSILENT PowerFactory which is a software tool for analyzing transmission system reliability. All data on individual network elements were taken from the report of the Croatian Transmission System Operator [13]. Usually, the information on a load at a monthly or, more often, at an annual basis is used to calculate the reliability of a power system. In this analysis, the information, i.e. loads of connection points and interconnection lines were chosen for a specific day. Two operating scenarios, for each load (maximum and minimum) were simulated in the program. The so-called load states were added to these scenarios. The load state is further used in the reliability assessment. The characteristics of the maximum and minimal loads are formed so that each of the twenty-four substations (loads) is assigned a characteristic of a one-dimensional vector which has related values in the period of one year.

\section{Comparison of the Maximum and Minimum Load Reliability Indicators}

When load states are set for the scenario of a maximum load, the reliability indicators are assessed, i.e. the reliability is assessed [7]. In the main menu of DIgSILENT program, one chooses Calculation $\rightarrow$ Reliability Assessment $\rightarrow$ Reliability Assessment. Firstly, one should make the assessment of the whole system (buses, lines, transformers) and then in the submenu Load Data choose the option Consider Load States, meaning that one should take into consideration load states (previously defined by characteristics). The corresponding reliability indicators for the maximum load are shown in Table 1.

As is the case with the maximum load, firstly Load states are created. The procedure is the same, and when the "MIN Load" scenario is active, it implies the active characteristics of a minimum substation load and the characteristics of transmission lines which remain unchanged. Table I shows the results of the minimum loads.

Some indicators, like EIC and IEAR will not be taken into consideration because they are not of technical but of economic character. We will graphically present the availability for a network set in this way and when the maximum load is connected.

TABLE I: THE COMPARATION OF RELIABILITY INDICATORS FOR

\begin{tabular}{lll}
\multicolumn{3}{c}{ DIFFERENT LOADS } \\
\hline \hline Indicators & Maximum Load & Minimum Load \\
\hline SAIFI & $2,401228[1 / \mathrm{C} / \mathrm{a}]$ & $2,400783[1 / \mathrm{C} / \mathrm{a}]$ \\
CAIFI & $2,401228[1 / \mathrm{C} / \mathrm{a}]$ & $2,400783[1 / \mathrm{C} / \mathrm{a}]$ \\
SAIDI & $0,259[\mathrm{~h} / \mathrm{C} / \mathrm{a}]$ & $0,259[\mathrm{~h} / \mathrm{C} / \mathrm{a}]$ \\
CAIDI & $0,108[\mathrm{~h}]$ & $0,108[\mathrm{~h}]$ \\
ASAI & 0,9999703937 & 0,9999704122 \\
ASUI & 0,0000296063 & 0,0000295878 \\
ENS & $77,971[\mathrm{MWh} / \mathrm{a}]$ & $40,171[\mathrm{MWh} / \mathrm{a}]$ \\
AENS & $3,249[\mathrm{MWh} / \mathrm{C} / \mathrm{a}]$ & $1,674[\mathrm{MWh} / \mathrm{C} / \mathrm{a}]$ \\
ASIFI & $2,1167221 / \mathrm{a}$ & $1,1052001 / \mathrm{a}$ \\
ASIDI & $0,197542 \mathrm{~h} / \mathrm{a}$ & $0,101775 \mathrm{~h} / \mathrm{a}$ \\
\hline \hline
\end{tabular}

SAIFI indicator represents the average frequency of system outages, i.e. it is a number of outages per customer in one year. As expected, in the minimum load scenario, there is a much lower value of indicators but by an insignificant value of $0,000,445$ [outages/customer, annually].

CAIFI indicator is the same as SAIFI indicator and it shows a number of outages in a year but per affected customer, whereas SAIFI shows a number of system outages in general. This means that outages are calculated for each customer once. The reason why CAIFI and SAIFI are the same for certain scenarios is the fact that the simulation of analysis views customer outages and system outages in the same way.

SAIDI indicator represents the index of average duration of system outages and CAIDI index represents the average duration of customer outages. There is no difference in the duration of outages for both indicators when they are viewed from the perspective of different scenarios. The total average duration of system outages for both cases is around 16 minutes annually, and the total duration of customer outages is 7 minutes annually.

ASAI indicator is the index of average availability of power supply, i.e. in relation to one observed year, it shows how much electricity was supplied to the given customer. Theoretically, the coefficient may range between 0 and 1 but in both scenarios, the coefficient has approximately the same value.

ASUI indicator is an inverse value of ASAI index and it represents the index of average unavailability of power supply, so the value of this index is higher for the case of the maximum load.

ENS indicator is the index of undelivered energy and for the scenario of the maximum load, it amounts to 77,971 [MWh/a], which is more than for the scenario of the minimum load when it amounts at 40,171 [MWh/a].

AENS represents the index of averagely undelivered energy, i.e. averagely undelivered energy per customer in one year. Just like ENS indicator, this value is higher for the case of the maximum load and it is 3,249 [MWh/customer]. 
In case of the minimum load, it is twice as low and it amounts to 1,674 [MWh/customer].

ASIFI indicator is the index of average frequency of system outages. In case of the maximum load, this index $(2,116,722$ outages/year) is twice as high as in the case of the minimum load (1,105,200 outages/year)

ASIDI indicator is the index of average duration of system outages. In case of the maximum load, this index $(0,197542$ hours/year) is twice as high as in the case of the minimum load (0,101775 outages/year).

Similarly, to ASIFI, ASIDI indicator, which represents the index of average duration of system outages, is higher in the case of the maximum load $(0,197,542$ hours/year) than in the case of the minimum load $(0,101,775$ hours/year).

The adequacy analyses (Fig. 2), with no Power Plants connected to the grid, show deficit in electricity availability.

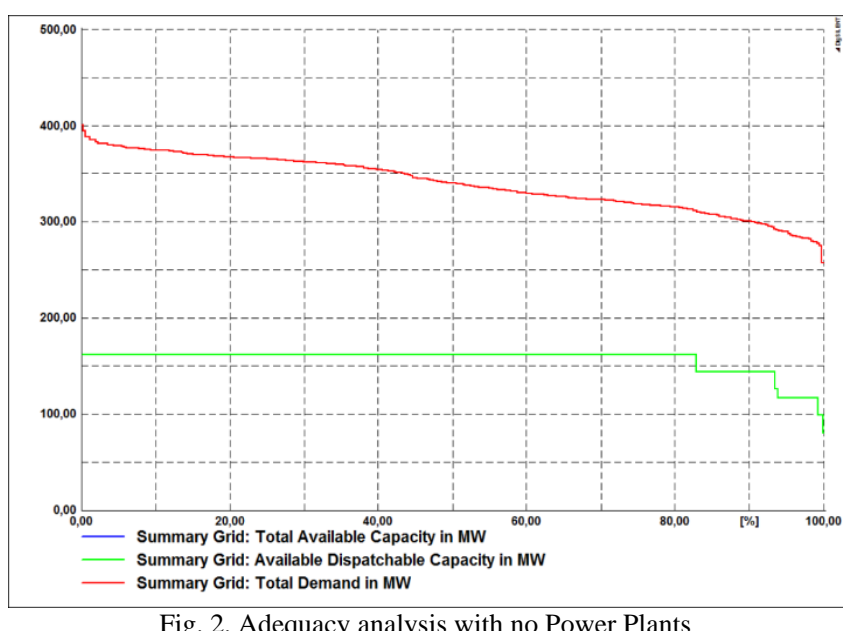

It is apparent that the current electricity demand is higher than the total value of available generation capacities.

\section{RELIABILITy ANALySiS FOR NEW POWER PlantS IN THE TRANSMISSION NETWORK}

This part of the paper will cover other reliability indicators, such as LOLP and EDNS and the availability for each simulation will be graphically presented. Since it is very difficult to calculate the indicators of reliability and availability of a power system as a whole, the system is divided into hierarchical levels of observation, such as generation, transmission and distribution. LOLP and EDNS indicators are calculated as a generator adequacy analysis with regard to the set stochastic model for generation in DIgSILENT. LOLP and EDNS are calculated according to the scenarios of the maximum load. Since ENS and AENS indicators almost double in the case of the maximum load, the analyses of reliability indicators' movements were calculated for that case. In this respect, the reliability indicators for the construction of three cogeneration facilities of lower power, like the reliability indicators in the case of construction of one cogeneration facility in different locations were calculated first.

\section{Reliability and Adequacy with Connected Small Sized CCGT}

Before starting the adequacy analysis, one must shape power flows in a transmission network with three small sized combined cogeneration plants (hereinafter CCGT). The power at buses, lines and transformers must be within stated limits $0.9-1.1$ p.u. The load of individual elements cannot exceed $95 \%$ of the maximum load. CCGTs are connected on three $110 \mathrm{kV}$ buses via block transformers and lines (cables). The first power plant is connected to bus Brod 1, the second to bus Vinkovci 1 and the third to bus Vukovar. Technical data of CCGT units are shown in Table II

TABLE I: THE TECHNICAL DATA OF SMALLER SizED CCGT UNITS VUKOVAR, VINKOVCI AND BROD

\begin{tabular}{|c|c|c|c|c|}
\hline $\begin{array}{l}\text { Equipment } \\
\text { /data } \\
\end{array}$ & $\begin{array}{l}\text { Rated } \\
\text { capacity }\end{array}$ & $\begin{array}{l}\text { Rated } \\
\text { voltage }\end{array}$ & Load factor & $\begin{array}{l}\text { Grounding } \\
\text { connection }\end{array}$ \\
\hline CCGT & $150 \mathrm{MW}$ & $10 \mathrm{kV}$ & $\begin{array}{l}0.95 \\
\text { inductive }\end{array}$ & YN \\
\hline \multirow{3}{*}{$\begin{array}{l}\text { Transfor- } \\
\text { mer }\end{array}$} & & & Connection & uk\% \\
\hline & 200 MVA & $10 / 110 \mathrm{kV}$ & DYn & $11 \%$ \\
\hline & Length & & $\begin{array}{l}\text { Rated } \\
\text { current }\end{array}$ & $\begin{array}{l}\text { Unit } \\
\text { reactance }\end{array}$ \\
\hline Line (cable) & $0.5 \mathrm{~km}$ & $110 \mathrm{kV}$ & $548 \mathrm{kA}$ & $0.113^{\Omega} / \mathrm{m}$ \\
\hline
\end{tabular}

The adequacy analysis for the case of connecting three smaller CCGTs, like for the case of connecting bigger unit, CCGTs is calculated in the scenarios of the maximum loads. To calculate the different adequacy indicators, it is necessary to define generator's condition, i.e. the stochastic model of generation, which shows how much time and which adequacy individual generators will work with. All generators of smaller power plants are with availability data presented in Table II.

TABLE II: THE AVAILABILITY OF SMALL SIZED CCGT

\begin{tabular}{ccc}
\hline \hline Stages & $\begin{array}{c}\text { Available } \\
\text { capacity } \\
(\%)\end{array}$ & $\begin{array}{c}\text { Probability } \\
(\%)\end{array}$ \\
\hline 1 & 0 & 16,5 \\
2 & 80 & 71,5 \\
3 & 100 & 12 \\
\hline \hline
\end{tabular}

Condition under number 1 , i.e. the condition in which a power plant is available with $0 \%$ of power, implies the time of an outage and overhaul in an observed year. The probabilities according to which the power plant operates with $71.5 \%$ of power and $100 \%$ power are given randomly, but basically, there is a much higher probability that the power plant will not operate with full power in the majority of cases. After setting all the necessary parameters, the generation adequacy analysis is conducted. When starting the simulation, system losses must be defined; in this model, they are set on a 3\% level (the plan of plant maintenance taken into consideration as well as the characteristics of a system load in the maximum load scenario). The number of iterations necessary for calculation is set to 100,000 runs. 


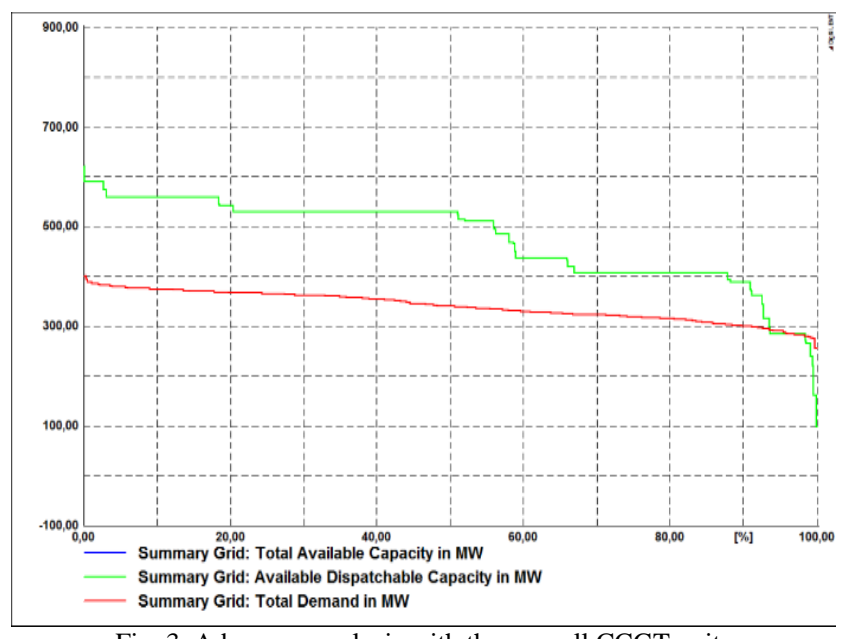

Fig. 3. Adequacy analysis with three small CCGT units

The adequacy calculation defined that the probability of power lack, i.e. $L O L P$, in this case totals at $13.598 \%$ and the expected undelivered energy, i.e. EDNS is 10.738 MWh. It is visible that generation capacities will be sufficient to customers' demand $90 \%$ of the time (Fig. 3).

In the case of ENS convergence, regarding the iteration number (Fig. 4), there are practically no changes of ENS values after 50,000 iterations.

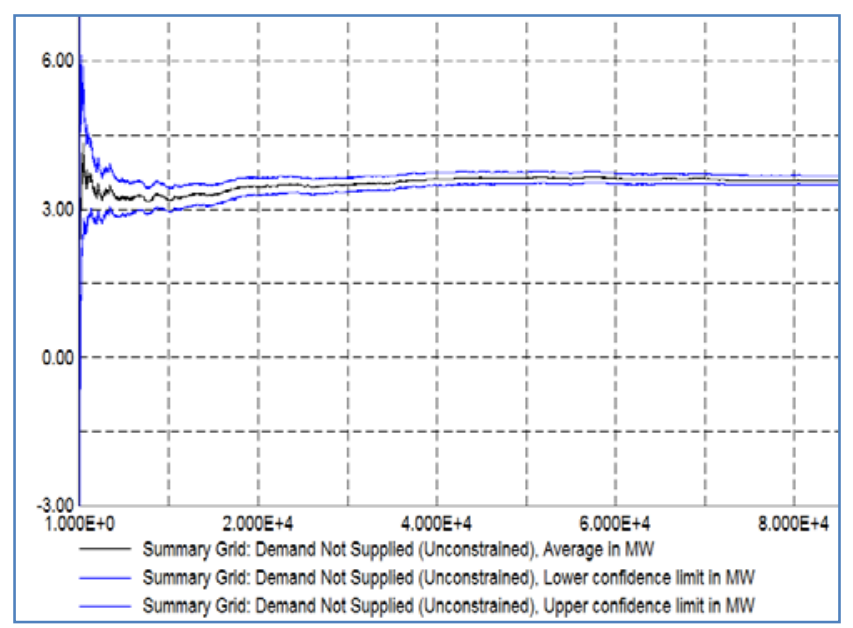

Fig. 4. ENS convergence in the case of three small sized CCGT units

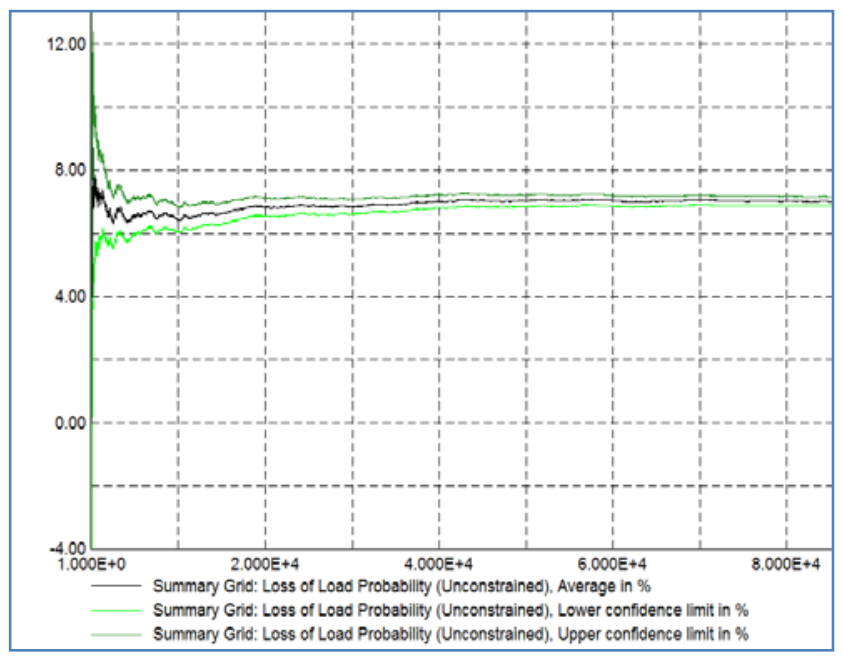

Fig. 5. LOLP convergence in the case of three small sized CCGT units
In the case of $L O L P$ calculation convergence (Fig. 5), there are practically no changes of LOLP values after 50,000 iterations.

\section{ADEQUACY ANALYSIS FROM CONNECTED CCGT BROD}

Combined Cycle Gas Turbine (CCGT) plant Brod has a significantly higher rated capacity than the thermal power plants analyzed before. It is also connected to the $400 \mathrm{kV}$ network junction. Although the reliability indicators for this unit are the same as the ones for the prior analyzed thermal power plants of lower rated capacity, the total reliability indicators for the observed network are much different. The following table contains technical data for the modelled thermal power plant.

TABLE III: THE TECHNICAL DATA OF HUGE SIZED CCGT UNITS ERNESTINOVO AND BROD

\begin{tabular}{lllll}
\hline $\begin{array}{l}\text { Equipme } \\
\text { nt } \\
\text { /data }\end{array}$ & $\begin{array}{l}\text { Rated } \\
\text { capacity }\end{array}$ & $\begin{array}{l}\text { Rated } \\
\text { voltage }\end{array}$ & Load factor & $\begin{array}{l}\text { Grounding } \\
\text { connection }\end{array}$ \\
\hline CCGT & $450 \mathrm{MW}$ & $20 \mathrm{kV}$ & $\begin{array}{l}1 \text { inductive } \\
\text { Connection }\end{array}$ & $\begin{array}{l}\text { YN } \\
\text { uk\% }\end{array}$ \\
$\begin{array}{l}\text { Transfor- } \\
\text { mer }\end{array}$ & $500 \mathrm{MVA}$ & $20 / 400 \mathrm{kV}$ & DYn & $12 \%$ \\
& Length & $\begin{array}{l}\text { Rated } \\
\text { voltage }\end{array}$ & $\begin{array}{l}\text { Rated } \\
\text { current }\end{array}$ & $\begin{array}{l}\text { Unit } \\
\text { reactance }\end{array}$ \\
OHL & $60 \mathrm{~km}$ & $400 \mathrm{kV}$ & $1.92 \mathrm{kA}$ & $0.3285 \Omega / m$ \\
\hline \hline
\end{tabular}

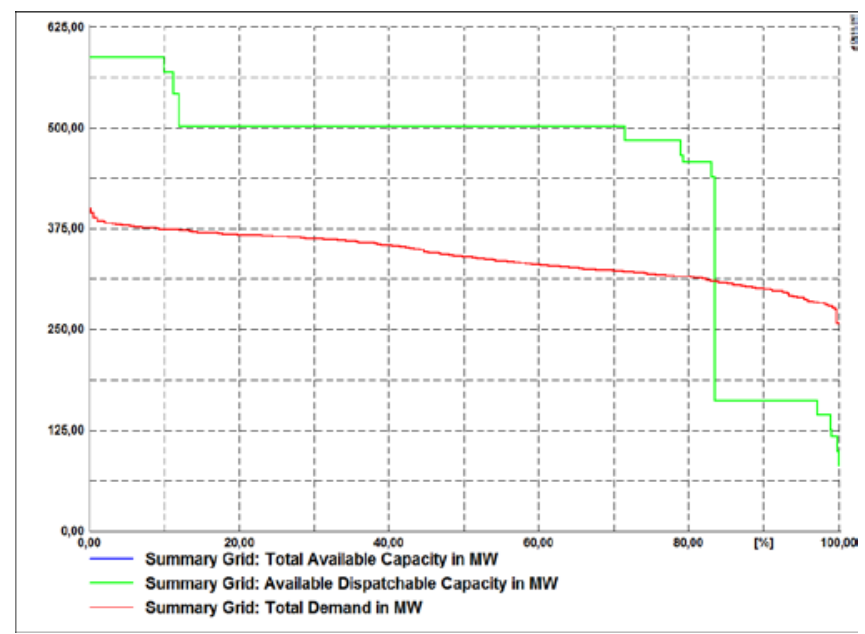

Fig. 6. Adequacy analysis from CCGT Brod unit

The adequacy calculation defined that the probability of power deficit, i.e. $L O L P$, in this case amounts to $17.188 \%$ (Fig. 6), and the expected undelivered energy, i.e. EDNS, amounts to $42.645 \mathrm{MWh}$. It is visible that the generation capacities will be sufficient to customers' demand $77 \%$ of time.

\section{Adequacy ANALysis FROM CONNECTED CCGT ERNESTINOVO}

This part simulates the construction of a combined gas and heat power plant of high power, which is connected to a 400-KV transformer substation Ernestinovo. Technical data for that thermal power plant are presented in the following table. 


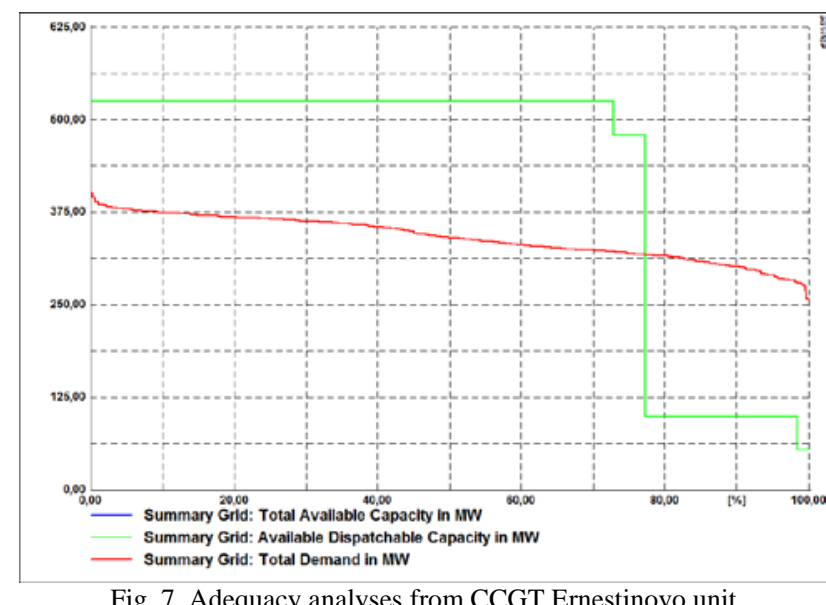

Fig. 7. Adequacy analyses from CCGT Ernestinovo unit

The calculation of adequacy defined that the probability of power deficit, i.e. $L O L P$, in this case totals at $17.047 \%$ (Fig. 7), and the expected undelivered energy, i.e. EDNS, totals at $42.196 \mathrm{MWh}$. It is apparent that the generation capacities will be sufficient to customers' demand $77 \%$ of time.

\section{Comparison of the Adequacy Analysis Results}

The following table presents the comparison of the results of generation adequacy simulation and undelivered electricity for different thermal power plants connected on various network junction points

TABLE IV: THE AVAILABILITY OF SMALL SIZED CCGT

\begin{tabular}{lccc}
\hline \multicolumn{1}{c}{ Power plant } & \multicolumn{3}{c}{ Lad indices } \\
& Maximum \\
\hline & LOLP & \multicolumn{2}{c}{ Reliability } \\
& 13.598 & Upper & Lower \\
\hline CCGT 3X150 MW & 13,41969 & 13,77631 \\
CGT Ernest. & 17.047 & 16,85138 & 17,24262 \\
CCGT Brod & 17.188 & 16,99174 & 17,38426 \\
& & & \\
CCGT 3X150 & & & \\
MW & & 10,738 & 10,552 \\
CGT Ernest. & & 42,196 & 41,698 \\
CCGT Brod & & 42,645 & 42,146 \\
\hline \hline
\end{tabular}

From the results, one may draw a conclusion that from the perspective of generation adequacy, there is the smallest Loss of Load Probability in the case of three units of 150 MW CCGTs. The reason for it lies in the fact that small power plants with their powers enter particular locations Slavonski Brod, Vinkovci and Vukovar. Bigger unit CCGTs enter in junction points Ernestinovo in one case and Slavonski Brod in another case at a higher voltage level, so it is "more difficult" to distribute electricity to customers.

\section{CONCLUSION}

This paper analyzed the influence of new power plants in the transmission network pf transmission area in Easter Croatia on reliability indicators. It dealt with the cases including no power plants and their reflection on systemic and energetic indicators depending on the load. All indicators were better in the case of the minimum load, which is a logical result. In the second part, new power plants were introduced and their influence on the adequacy indicators was shown. From that point of view, the influence of smaller CCGTs is more favorable than the bigger one CCGT unit, which may clearly be seen from the comparison of the results. The probability of loss of load, $L O L P$ is lower in the case of three smaller CCGTs than in the case of the bigger unit of CCGT Brod or CCGT Ernestinovo. Also, the expected undelivered energy, ENS is a few times smaller in the case of three small CCGTs. On the basis of these results, one may conclude that, from the point of view of reliability and adequacy, it is better to incorporate three smaller combined cogeneration power plants in the transmission network as new capacities. Of course, when choosing the location and rated power of the thermal power plant, it is necessary to analyze a whole range of other parameters, such as economical, ecological and others.

\section{ACKNOWLEDGMENT}

Authors thanks to CTSO - Croatian Transmission System Operator for valuable data of transmission network.

\section{REFERENCES}

[1] J. Endrenyi, Reliability Modeling in Electric Power Systems, J. Wiley \& Sons, Chichester, 1978

[2] R. Billinton, R. N. Allan, Reliability assessment of large electric power systems, Kluwer Academic Publishers, 1988

[3] A. Chowdhury, D. Koval, Power Distribution System Reliability: Practical Methods and Applications. Wiley-IEEE Press, April 2009

[4] M. B. Hamouda, M. N. Lakhoua, Lilia El Amraoui "Dependability Evaluation and Supervision in Thermal Power Plants" International Journal of Electrical and Computer Engineering (IJECE), Vol.5, No.5, December 2015

[5] R. Billinton, W. Li, Reliability Assessment of Electric Power Systems Using Monte Carlo Methods, Plenum Press, New York. 1994

[6] L. Salvaderi, R. Billinton, “A Comparison Between Two Fundamentally Different Approaches to Composite System Reliability Evaluation”, IEEE Transactions on Power Apparatus and Systems, Jan. 1986

[7] W. Zhang, "Reliability Evaluation of Bulk Power Systems Using Analytical and Equivalent Approaches”, PhD dissertation, University of Saskatchewan, 1998

[8] M. Benidris, S. Elsaiah, J. Mitra, "Composite system reliability assessment using dynamically directed Particle Swarm Optimization“ In Proc. Conference: North American Power Symposium (NAPS), 2013

[9] R. Billinton, C. Singh, "System Load Representation in Generating Capacity Reliability Studies Part II Applications and Extensions”, IEEE Transactions on Power Apparatus and Systems, Issue 5, Sep. 1972

[10] Z. Deng, C. Singh, “A new approach to reliability evaluation of interconnected power systems including planned outages and frequency calculations”, IEEE Trans. on Power Systems, Vol. 7, No. 2, May 1992

[11] DIgSILENT PowerFactory 15,0 User manual, Gommaringen 2016

[12] Croatian TSO-Transmission System Operator topological data https://www.hops.hr/wps/portal/hr/web/hees/podaci/shema. accessed on May 12, 2016

[13] Croatian TSO "Statistical outage data in transmission network" Zagreb, 2014

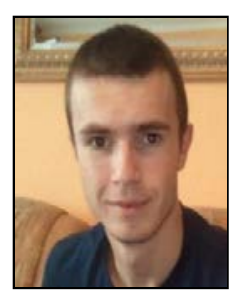

Anto Topić, MEng, was born in Orahovica, Bosnia and Herzegovina on August 17, 1992. He obtained his Bachelor degree (2014) and Master degree (2016) from the Faculty of Electrical Engineering, Computer Science and Information Technology, J. J. Strossmayer University of Osijek. His Master thesis dealt with the issue of reliability and adequacy. 


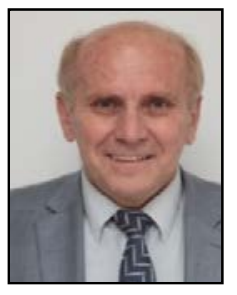

Srete Nikolovski, PhD. MSc. Dipl. Ing. (IEEE M' 1995, SM'2005) was born in Belgrade on October 1, 1954. He obtained his BSc degree (1978) and MSc degree (1989) in Electrical Engineering from the Faculty of Electrical Engineering, University of Belgrade and his $\mathrm{PhD}$ degree (1993) from the Faculty of Electrical Engineering and Computing, University of Zagreb, Croatia. He is currently a Full Professor at the Department of Power Engineering at the Faculty of Electrical Engineering, Computer Science and Information Technology, J. J. Strossmayer University of Osijek, Croatia. His main interests are power system protection, power system modeling, simulation and reliability. He has published 180 research papers in journals and international conference proceedings. He is an IEEE Senior member of Reliability Society and PES Society.

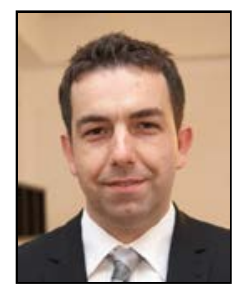

Emir Alibašić, MEng, was born in Tuzla on March 12, 1982. He obtained his Master degree (2007) from the Faculty of Electrical Engineering, University of Tuzla. He is currently a PhD student at the Faculty of Electrical Engineering, Computer Science and Information Technology, University of Osijek, Croatia. His main interests are power transmission lines and optimization of electrical energy. He was employed at UMEL-Dalekovod montaža on the position of designing and conducting business in the electricity objects up to $400 \mathrm{kV}$. He is owner INFORM Agency for the development of software applications. He currently works as an ITC manager in Tuzla county. 